\title{
Preparation and Characterization of Nanoscale Cobalt Blue Pigment for Ceramic Inkjet Printing by Sol-Gel Self-Propagating Combustion
}

\author{
Qi Tang ${ }^{a, b}$, Haixiang $Z h u^{b, c}$, Cheng Chen ${ }^{b}$, Yanxiang Wang ${ }^{c}$, Zhigang $Z \mathrm{Zh}^{b *}$, Jianqing Wu ${ }^{a}$, \\ Weiheng Shih ${ }^{d}$ \\ ${ }^{a}$ School of Materials Science and Engineering, South China University of Technology, 510641, \\ Guangzhou, China. \\ ${ }^{b}$ School of Environmental and Materials Engineering, College of Engineering, Shanghai Polytechnic \\ University, 201209, Shanghai, China. \\ ${ }^{c}$ School of Materials Science and Engineering, Jingdezhen Ceramic Institute, 333001, Jingdezhen, \\ Jiangxi, China. \\ ${ }^{d}$ Department of Materials Engineering, Drexel University, 19104, Philadelphia, Pennsylvania, \\ United States.
}

Received: March 27, 2017; Revised: May 25, 2017; Accepted: July 03, 2017

\begin{abstract}
Cobalt blue pigments were prepared by self-propagating combustion followed by sol-gel method using aluminum nitrate and cobalt nitrate as the raw material. X ray diffraction (XRD), scanning electron microscopy (SEM), fiber optic spectrometer and colorimetric analysis were used to investigate the effect of reaction temperature, metal ion concentration and dispersant upon the gel formation. The results show that the formation of gel network could be promoted by increasing the concentration of metal ion $(0.01 \sim 0.2 \mathrm{~mol} / \mathrm{L})$ and sol-gel reaction temperature $\left(80 \sim 90^{\circ} \mathrm{C}\right)$, and the disper-sibility and stability of the pigment powder could be improved with dispersing agent. The dried gel precursor was calcined at $1250^{\circ} \mathrm{C}$ to form $200 \sim 500 \mathrm{~nm}$ cobalt aluminum with spinel structure with highly negative value of $b^{*}$.
\end{abstract}

Keywords: sol-gel method, self-propagating combustion, cobalt aluminate spinel, cobalt blue pigment

\section{Introduction}

Inkjet printing technology has been rapidly developed for the ceramic tile decoration. It allows flexible design and control of printing images, inks and substrates with higher surface coverage, and high number of reflectance points ${ }^{1}$. One of the urgent problems for ceramic inkjet printing is the development of the ceramic ink due to the demand for ceramic tile products with high-resolution images. Ceramic cobalt blue pigments such as $\mathrm{Co}_{2} \mathrm{SiO}_{4}$ (olivine), $\mathrm{Co}_{2} \mathrm{SiO}_{4}$ (willemite) and $\mathrm{Co}_{3-\mathrm{s}} \mathrm{Al}_{\mathrm{s}} \mathrm{O}_{4}$ (cobalt spinel, $\mathrm{s}=0,1,2$ and 3) have received significant attention due to their superior properties such as high refractive index, refractory, color and chemical stability. For example, $\mathrm{CoAl}_{2} \mathrm{O}_{4}$ is the most stable structure of the spinel-type crystal family, wherein the tetrahedral sites are occupied by $\mathrm{Co}^{2+}$ and the octahedral sites by the $\mathrm{Al}^{3+2-4}$.

Several methods have been developed for the synthesis of cobalt-blue based systems. The most common methods include sol-gel method, solid-state reaction, micro-emulsion, co-precipitation and polymeric precursor method ${ }^{5,6}$. Sol-gel is high reproducibility and low cost method, which utilize high active compound as precursor, and the raw materials are well mixed in the liquid which undergo hydrolysis to form transparent and stable sol system. The sol system is able to form three-dimensional network structure after aging, and thus produce uniform nano powder through drying and heat treatment. Chemlal et al. prepared cobalt aluminate $\mathrm{CoAl}_{2} \mathrm{O}_{4}$ by utilizing sol-gel method, where $\mathrm{HNO}_{3}, \mathrm{Al}_{2} \mathrm{O}_{3}$ and $\mathrm{CoCl}_{2} \cdot 6 \mathrm{H}_{2} \mathrm{O}$ were selected as raw materials, and discussed the influence of $\mathrm{pH}$ value upon the crystallization and surface properties of $\mathrm{CoAl}_{2} \mathrm{O}_{4}^{7}$. Cui et al. synthesized a series of spinel nanoparticles through sol-gel route and studied their particle size and size distributions ${ }^{8}$.

In this study, cobalt blue pigment precursor was prepared by a sol-gel method using aluminum nitrate and cobalt nitrate as raw materials. It was shown that the spinel cobalt aluminate $\mathrm{CoAl}_{2} \mathrm{O}_{4}$ with strong blue color were prepared without any dopants. The effects of calcination temperature, the concentration of metal ion, selection of dispersant on microstructure and colorimetric data of the pigments were investigated and used to improve the physical properties. In addition, it is shown that the sol-gel method produces $\mathrm{CoAl}_{2} \mathrm{O}_{4}$ powders that have better particle distribution and dispersity than the solid-state reaction method. 


\section{Experimental}

\subsection{Chemicals and materials}

Cobalt nitrate $\left(\mathrm{Co}\left(\mathrm{NO}_{3}\right)_{2} \cdot 6 \mathrm{H}_{2} \mathrm{O}\right)$, aluminum nitrate $\left(\mathrm{Al}\left(\mathrm{NO}_{3}\right)_{3} \cdot 9 \mathrm{H}_{2} \mathrm{O}\right)$, ethylene glycol $\left(\mathrm{EG}, \mathrm{C}_{2} \mathrm{H}_{6} \mathrm{O}_{2}\right)$, glycerol $\left(\mathrm{GC}, \mathrm{C}_{3} \mathrm{H}_{8} \mathrm{O}_{3}\right)$, ammonia $\left(\mathrm{NH}_{3} \cdot \mathrm{H}_{2} \mathrm{O}\right)$ and citric acid $\left(\mathrm{C}_{6} \mathrm{H}_{8} \mathrm{O}_{7}\right)$ were purchased from Sinopharm Chemical Reagent Co., Ltd. and used as received without further purification. Ultra-pure water was used in all experiments $(18.2 \mathrm{M} \Omega \cdot \mathrm{cm})$.

\subsection{Sample preparation}

Firstly, a precursor solution including cobalt nitrate and aluminum nitrate with molar ratio of 1:2 was prepared at $75^{\circ} \mathrm{C}$, a mixture of citric acid and dispersant (ethylene glycol or glycerol) with molar ratio of 1:1 was then added, and the precursor solution was gently stirred for $2 \mathrm{~h}$. An ammonia solution was added dropwise to adjust the $\mathrm{pH}$ value to 6.5 , and the solution was allowed to evaporate in a $40 \sim 90{ }^{\circ} \mathrm{C}$ water bath. After the solution was gelated, a transparent gel was obtained, and the resultant was filtered off, washed and dried overnight at $110^{\circ} \mathrm{C}$. Then, the dry gel was placed in an oven at $300{ }^{\circ} \mathrm{C}$ for $5 \mathrm{~h}$, and black precursor (loose powder) was obtained after the self propagating combustion. The resulting powder was calcined at $900 \sim 1250{ }^{\circ} \mathrm{C}$ in a muffle furnace for 60 minutes, and the cobalt blue pigment was obtained after the thermal treatment.

\subsection{Characterization}

Automatic colorimeter (SC-80C, Beijing Kangguang Optical Instrument Co., Ltd.) was used to measure the color factors, $L^{*}, a^{*}$ and $b^{*}$. The CIELab colorimetric method, recommended by the Commission Internationale de l'Eclairage, was used. Two mutual orthogonal axes, $a^{*}$ and $b^{*}$, represent the hue or color dimensions. The third axis, lightness $\left(L^{*}\right)$, is perpendicular to the $a^{*}$ and $b^{*}$ plane and has a value of 0 for black and 100 for white. Positive $a^{*}$ value corresponds to red color, while negative value to green color. At the meantime, Positive $b^{*}$ value corresponds to yellow color, while negative value to blue color ${ }^{9}$. Fiber optic spectrophotometer (USB4000- XR1-ES, Ocean Optics) was used to determine the reflection intensity, spectra were recorded in the wavelength range between 350 and $900 \mathrm{~nm}$. X-ray diffraction (XRD, D8 Advance, Bruker) with $\mathrm{Cu} \mathrm{K}$ radiation $\left(\lambda=1.5418 \AA\right.$ ) was conducted from $20^{\circ}$ to $70^{\circ}$ for the qualitative phase analysis of the pigment. Structural and morphological characterizations were performed using a field emission scanning electron microscope (FESEM, S-4800, Hitachi), operating at an acceleration voltage of $3-5 \mathrm{kV}$.

\section{Results and Discussion}

\subsection{Effect of sol-gel temperature}

The temperature dependence of the gel forming time was first studied, as shown in Fig. 1. The gel formation started once the temperature reached to $65{ }^{\circ} \mathrm{C}$ and the whole process could be completed after $13.5 \mathrm{~h}$, and the complexation reaction between the metal ion and citric acid was not able to occur if the temperature is lower than $65^{\circ} \mathrm{C}$. The gelation time was greatly reduced as the reaction temperature increased, and the whole gelation process could be shortened to $3.5 \mathrm{~h}$ while the temperature was $90{ }^{\circ} \mathrm{C}$. However, further increasing the temperature led to form uniform gel, which is mainly due to fast evaporation of the water. Therefore, the optimized sol-gel reaction temperature is $80 \sim 90{ }^{\circ} \mathrm{C}$.

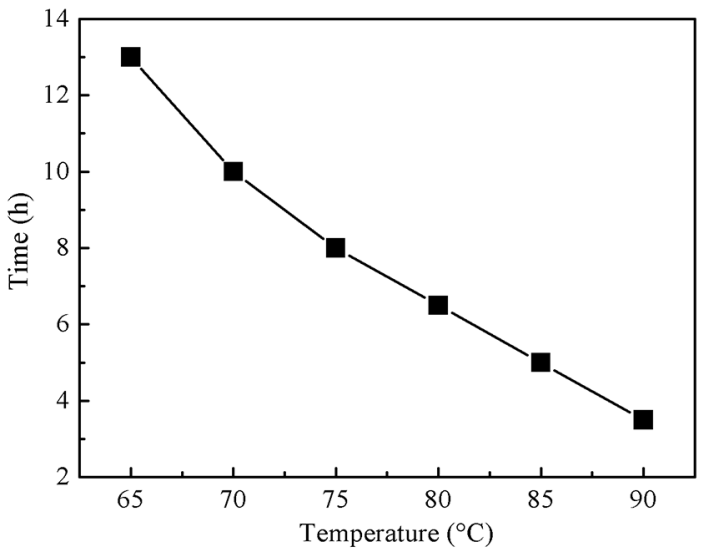

Figure 1. Effect of temperature on the gel forming time.

\subsection{Effect of metal ion concentration}

The effect of metal ion concentration on gelation time is shown in Fig. 2. The $\mathrm{Al}^{3+}: \mathrm{Co}^{2+}$ molar ratio was fixed at $1: 2$ and the concentration of $\mathrm{Co}^{2+}$ ions varied from $0.01 \mathrm{~mol} / \mathrm{L}$ to $0.2 \mathrm{~mol} / \mathrm{L}$ during the preparation. It is obvious that the gelation time was dramatically shortened from $13 \mathrm{~h}$ to 1.5 $\mathrm{h}$, as the $\mathrm{Co}^{2+}$ concentration increased from $0.01 \mathrm{~mol} / \mathrm{L}$ to $0.2 \mathrm{~mol} / \mathrm{L}$. This suggests that the increase of total content of metal ions promoting the gel formation. It is speculated that the presence of $\mathrm{Co}^{2+}$ reduces the intermolecular repulsion and reduces the molecular hydration, which facilitates the formation of three-dimensional network structures. These samples were calcined at $1150{ }^{\circ} \mathrm{C}$ and the resulting blue pigments were further studied. 


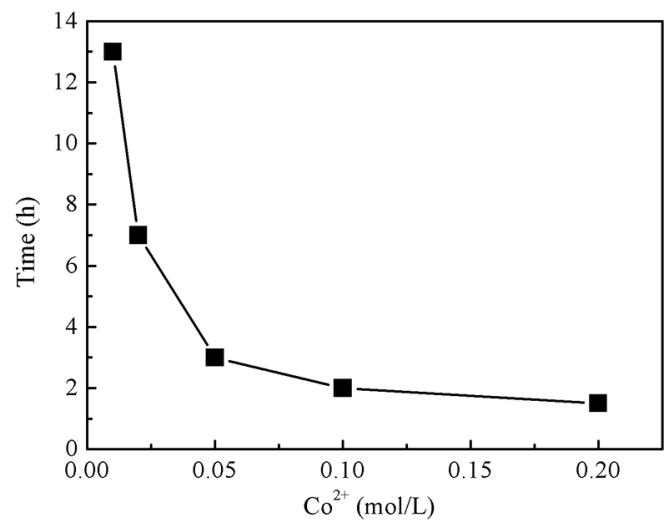

Figure 2. Effect of metal ion concentration on gelation time.

The colorimetric data in Table 1 summarized the color performance of the pigments prepared with varied metal ion content. It can be found that the $b^{*}$ value increased from -21.73 to -25.45 , while $a^{*}$ value decreased from -20.53 to -19.18 , as the increase of $\mathrm{Co}^{2+}$ concentration. This indicates that the pigment with $0.2 \mathrm{~mol} / \mathrm{L} \mathrm{Co}^{2+}$ corresponded more to blue color $\left(b^{*}=-25.45\right)$, and less to green color $\left(a^{*}=-19.18\right)$. On the other hand, the lightness of the pigment is governed by the coordinate parameter $L^{*}$, the higher $\mathrm{Co}^{2+}$ concentration also resulted in a higher $L^{*}$ value, i.e. the pigment was lighter.

Table 1. The colorimetric data for cobalt blue pigments with different metal ions concentration.

\begin{tabular}{ccccc}
\hline Samples & $\begin{array}{c}\mathrm{Co}^{2+} \text { concentration } \\
(\mathrm{mol} / \mathrm{L})\end{array}$ & $L^{*}$ & $a^{*}$ & $b^{*}$ \\
\hline $\mathrm{B}_{1}$ & 0.01 & 43.69 & -20.53 & -21.73 \\
$\mathrm{~B}_{2}$ & 0.05 & 44.79 & -20.45 & -23.03 \\
$\mathrm{~B}_{3}$ & 0.10 & 44.70 & -19.56 & -24.19 \\
$\mathrm{~B}_{4}$ & 0.20 & 45.55 & -19.18 & -25.45 \\
\hline
\end{tabular}

The effects of metal ions on color performance could be mainly attributed to the complexation reaction between $\mathrm{Co}^{2+}, \mathrm{Al}^{3+}$ and citric acid during preparation. Small amount of metal ion resulted in lower complexes content and the gelation was thus not homogenous, which affected the self-propagating combustion and the formation of the spinel structure. Furthermore, the reflection spectra of the blue pigments were depicted in Fig. 3. The intensity of the reflection peak at $436 \mathrm{~nm}$ (blue) increased with the increasing of $\mathrm{Co}^{2+}$ content, and the maximum value is 3530.70 . This result is consistent with the colorimetric data in Table 1 .

\subsection{Effect of the dispersants}

The ethylene glycol (EG) and glycerol (GC) were used as dispersant during sol-gel process to avoid the aggregation. Fig. 4 shows the morphology of the pigments using different

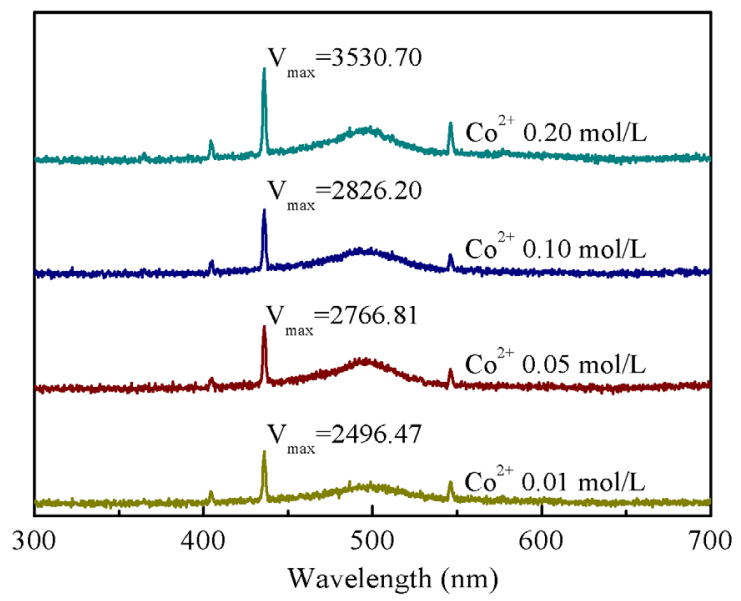

Figure 3. Reflective intensity of the samples with different metal ions concentration.

dispersants and being calcined at $1150{ }^{\circ} \mathrm{C}$. It could be found that the use of organic dispersants, like EG and GC, resulted in homogeneous distribution of cobalt powder, while GC performed better than EG. One possible reason is that the EG and $\mathrm{GC}$ form hydrogen bonds with - $\mathrm{COOH}$ groups of citric acid, and it can be further suffered an esterification reaction during high temperature, which is benefit to the formation of the gel network. Another reason is that $-\mathrm{OH}$ groups in EG and GC could effectively retard the colloidal particles gathering together and thus greatly reduce aggregation. The $-\mathrm{OH}$ group in $\mathrm{GC}$ is 1.5 times more than that in $\mathrm{EG}$, therefore, the addition of dispersant GC produce uniform pigment particles than EG. The colorimetric data of the pigments prepared with different dispersants was presented in Table 2. It is observed that for $b^{*}$ coordinate, it kept highly negative value for both samples used dispersants, and the better performance of the sample with GC is resulted from the uniform cobalt powder particle.
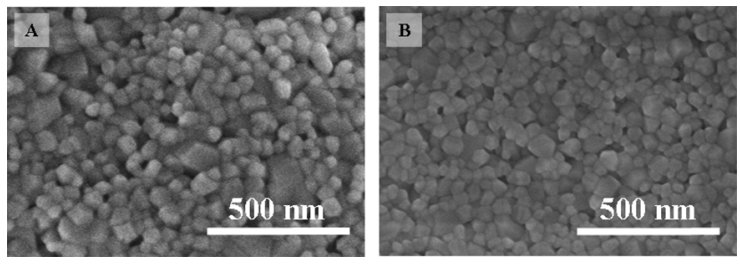

Figure 4. SEM images of the cobalt blue pigment samples calcined at $1150{ }^{\circ} \mathrm{C}$ using different dispersants: (A) EG and (B) GC. The scale bars are $500 \mathrm{~nm}$ in length.

Table 2. The colorimetric data for cobalt blue pigments with different dispersant.

\begin{tabular}{ccccc}
\hline Samples & Dispersant & $L^{*}$ & $a^{*}$ & $b^{*}$ \\
\hline A-1150 & EG & 47.15 & -16.01 & -22.08 \\
B-1150 & GC & 46.75 & -20.33 & -23.52 \\
\hline
\end{tabular}




\subsection{Effect of calcination temperature}

The XRD pattern are presented in Fig. 5, and it demonstrated that the powder synthesized at different temperature both have spinel $\mathrm{CoAl}_{2} \mathrm{O}_{4}$ structure, according to JCPDS card (No. 44-0160). However, the crystallinity of specimen calcined at $900{ }^{\circ} \mathrm{C}$ spinel is much less than that calcined at $1150^{\circ} \mathrm{C}$.

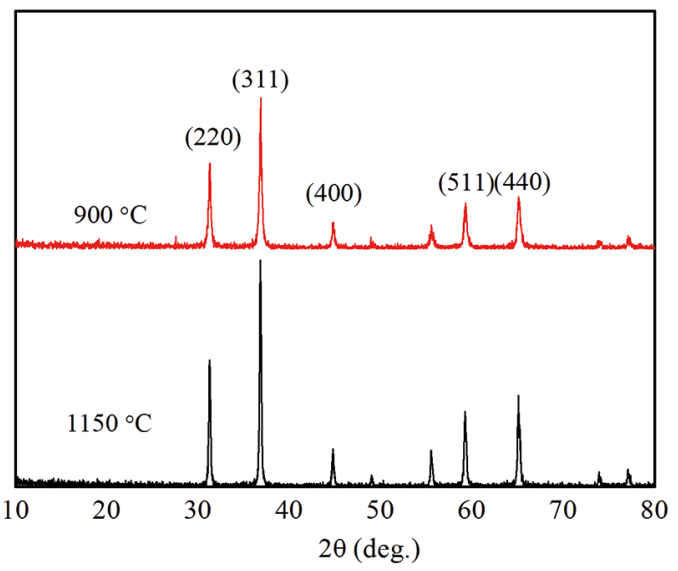

Figure 5. XRD patterns of the pigments calcined at different temperature.

Fig. 6 shows the SEM micrographs of cobalt blue pigments calcined at $900{ }^{\circ} \mathrm{C}, 1050{ }^{\circ} \mathrm{C}, 1150{ }^{\circ} \mathrm{C}$ (see Fig. 4B) and $1250^{\circ} \mathrm{C}$. As can be seen, the crystallization of the pigment particles initialed from $900{ }^{\circ} \mathrm{C}$ and the particle size was $40 \sim 50 \mathrm{~nm}$, and with the increase of calcining temperature, the product revealed more uniform crystal structure, and the grain grew gradually from tens to hundreds of $\mathrm{nm}$.
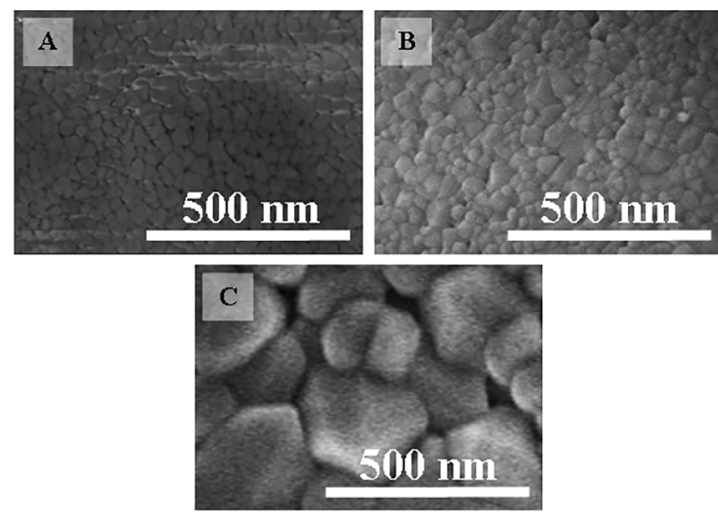

Figure 6. SEM micrographs of pigments calcined at (A) $900{ }^{\circ} \mathrm{C}$, (B) $1050{ }^{\circ} \mathrm{C}$ and (C) $1250^{\circ} \mathrm{C}$. The scale bars are $500 \mathrm{~nm}$ in length.

We studied the influence of the calcination temperature on the color performance of the pigments. After self-propagating combustion, the black powder was separated and calcined for 60 mins at $900{ }^{\circ} \mathrm{C}, 1050{ }^{\circ} \mathrm{C}, 1150{ }^{\circ} \mathrm{C}$ and $1250{ }^{\circ} \mathrm{C}$, respectively. The experimental results were listed in Table 3 . It is obvious that different calcination temperatures resulted in different color performances of the pigments. At $900^{\circ} \mathrm{C}$, the coordinate $a^{*}$ was greater than the coordinate $b^{*}$, and the pigment was dark green. With the increase of calcination temperature, the coordinate $b^{*}$ value increased and $a^{*}$ gradually decreased, and the color of pigment changed from dark green through dark blue to bright blue. It is found in Fig. 7, the intensity of the reflection peak at $436 \mathrm{~nm}$ (blue) increased with the increasing of calcination temperature which is consistent with the colorimetric data. It revealed that the calcination temperature remarkably affects the color of the product and the coordinate $b^{*}$ reached -43.06 as the calcination temperature was raised to $1250^{\circ} \mathrm{C}$. This result is better than previous reported works, such as $\mathrm{Co}_{0.95} \mathrm{Zn}_{0.05} \mathrm{Al}_{2} \mathrm{O}_{4}$ $\operatorname{system}\left(b^{*}=-29.54\right)^{4}, \mathrm{Co}_{0.5} \mathrm{Zn}_{0.5} \mathrm{Al}_{2} \mathrm{O}_{4}$ system $\left(b^{*}=-36.24\right)^{6}$ and $\mathrm{Mg}_{0.8} \mathrm{Co}_{0.2} \mathrm{Al}_{2} \mathrm{O}_{4}$ pigment $\left(b^{*}=-41.67\right)^{10}$.

Table 3. The colorimetric data for cobalt blue pigments calcined at different temperature.

\begin{tabular}{ccccc}
\hline Samples & $\begin{array}{c}\text { Calcination Temperature } \\
\left({ }^{\circ} \mathrm{C}\right)\end{array}$ & $L^{*}$ & $a^{*}$ & $b^{*}$ \\
\hline B-900 & 900 & 35.42 & -24.15 & -15.37 \\
B-1050 & 1050 & 46.65 & -20.45 & -22.34 \\
B-1150 & 1150 & 46.75 & -20.33 & -23.52 \\
B-1250 & 1250 & 44.39 & -8.73 & -43.06 \\
\hline
\end{tabular}

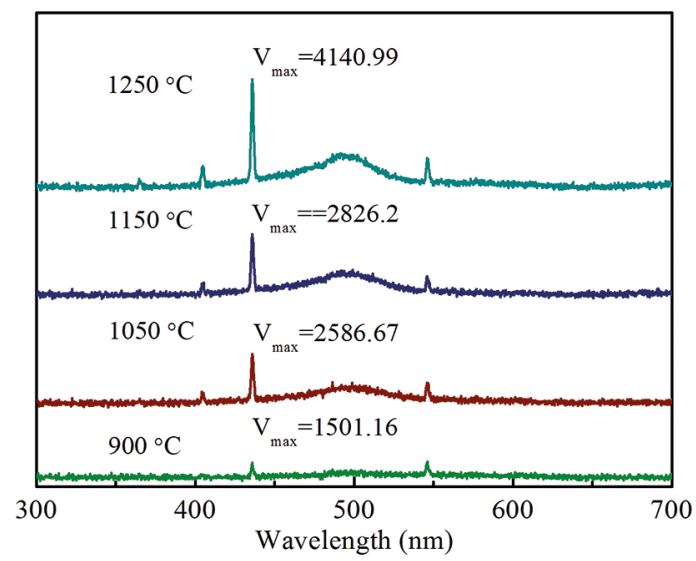

Figure 7. Reflective intensity of the pigments calcined at different temperature.

\section{Conclusions}

In conclusion, high purity cobalt blue pigments with spinel structure were prepared by sol-gel method followed by self-propagating combustion. The results show that the formation of gel network could be promoted by increasing the concentration of metal ion $(0.01 \sim 0.2 \mathrm{~mol} / \mathrm{L})$ and sol-gel reaction temperature $\left(80 \sim 90^{\circ} \mathrm{C}\right)$. The dispersibility and stability of the pigment powder could be improved with introducing 
glycerol as dispersant. The particle size of the pigment increases with the increasing of calcination temperature, and the $b^{*}$ value of the pigment could be reached as high as -43.06 at $1250^{\circ} \mathrm{C}$, which is higher than previous results. This is a facile route to produce $\mathrm{CoAl}_{2} \mathrm{O}_{4}$ powders without introducing any dopants, and it has better particle distribution and dispersity than traditional solid-state reaction.

\section{Acknowledgments}

This work was supported by the National Natural Science Foundation of China (61471233, 21504051), the Program for Professor of Special Appointment (Eastern Scholar) at Shanghai Institutions of Higher Learning, the Shuguang and YangFan Project from Science and Technology Commission of Shanghai Municipality (14SG52, 14YF1410600).

\section{References}

1. Derby B. Inkjet printing ceramics: From drops to solid. Journal of the European Ceramic Society. 2011;31(14):2543-2550.

2. Chen Z, Shi E, Li W, Zheng Y, Zhong W. Hydrothermal synthesis and optical property of nano-sized $\mathrm{CoAl}_{2} \mathrm{O}_{4}$ pigment. Materials Letters. 2002;55(5):281-284.

3. Nakatsuka A, Ikeda Y, Yamasaki Y, Nakayama N, Mizota T. Cation distribution and bond lengths in $\mathrm{CoAl}_{2} \mathrm{O}_{4}$ spinel. Solid State Communications. 2003;128(2-3):85-90.
4. Chen YX, Hu Q, Cao CE, Lu XL, Hong C, Shen HR. Effects of $\mathrm{Zn}^{2+}$ and $\mathrm{Cr}^{3+}$ doping on nano-sized $\mathrm{CoAl}_{2} \mathrm{O}_{4}$ spinel pigments by hydrothermal processing. Journal of Inorganic Materials. 2012;27(12):1317-1320.

5. Srisawad N, Chaitree W, Mekasuwandumrong O, Praserthdam $\mathrm{P}$, Panpranot J. Formation of $\mathrm{CoAl}_{2} \mathrm{O}_{4}$ nanoparticles via low-temperature solid-state reaction of fine gibbsite and cobalt precursor. Journal of Nanomaterials. 2012;2012:108369.

6. de Souza LKC, Zamian JR, da Rocha Filho GN, Soledade LEB, dos Santos I MG, Souza AG, et al. Blue pigments based on $\mathrm{CoxZn} \mathrm{n}_{1-\mathrm{x}} \mathrm{Al}_{2} \mathrm{O}_{4}$ spinels synthesized by the polymeric precursor method. Dyes and Pigments. 2009;81(3):187-192.

7. Chemlal S, Larbot A, Persin M, Sarrazin J, Sghyara M, Rafiq M. Cobalt spinel $\mathrm{CoAl}_{2} \mathrm{O}_{4}$ via sol-gel process: elaboration and surface properties. Materials Research Bulletin. 2000;35(14-15):25152523.

8. Cui H, Zayat M, Levy D. Sol-Gel Synthesis of Nanoscaled Spinels Using Propylene Oxide as a Gelation Agent. Journal of Sol-Gel Science and Technology. 2005;35(3):175-181.

9. Eliziário SA, de Andrade JM, Lima SJG, Paskocimas CA, Soledade LEB, Hammer P, et al. Black and green pigments based on chromium-cobalt spinels. Materials Chemistry and Physics. 2011;129(1-2):619-624.

10. Ianoş R, Lazău R, Barvinschi P. Synthesis of $\mathrm{Mg}_{1-x} \mathrm{Co}_{x} \mathrm{Al}_{2} \mathrm{O}_{4}$ blue pigments via combustion route. Advanced Powder Technology. 2011;22(3):396-400. 